\title{
Can Gold be an Effective Catalyst for the Deacon Reaction?
}

\author{
Grazia Malta ${ }^{1}$ (1) - Simon R. Dawson ${ }^{1} \cdot$ Samuel Pattisson $^{1} \cdot$ Miles M. Edwards $^{1} \cdot$ Simon J. Freakley $^{1}$. \\ Nicholas F. Dummer ${ }^{1}\left(\mathbb{D} \cdot\right.$ Ekkehard Schwab $^{2} \cdot$ Michael Bender $^{2} \cdot$ J. Henrique Teles ${ }^{2}(\mathbb{D}) \cdot$ Graham J. Hutchings $^{1}(\mathbb{D})$
}

Received: 6 March 2020 / Accepted: 27 March 2020 / Published online: 8 April 2020

(c) The Author(s) 2020

\begin{abstract}
The Deacon reaction is an important industrial process for the oxidation of hydrogen chloride, thereby enabling chlorine to be recycled. As gold is an efficient catalyst for reactions involving hydrogen chloride and oxygen, we have studied the use of gold as a potential catalyst for the Deacon reaction. Unfortunately, gold displays only limited activity; however, this is markedly increased if hydrogen is cofed as a reactant.
\end{abstract}

\section{Graphic Abstract}

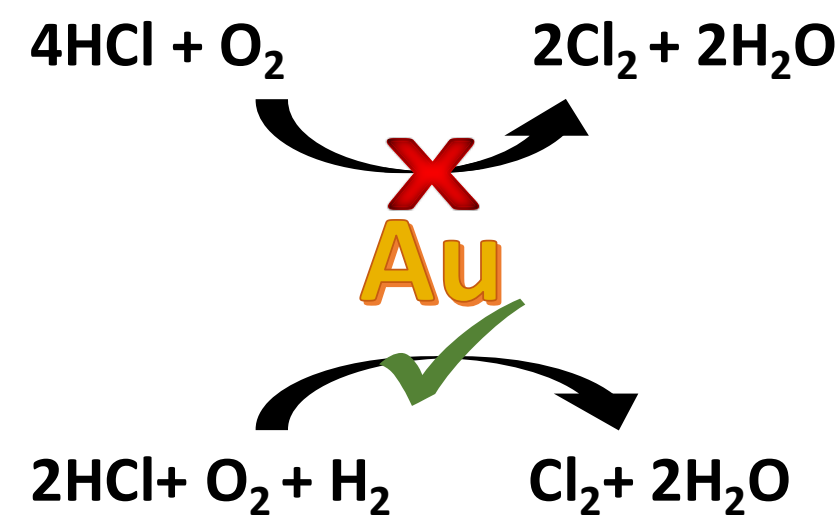

Keywords Deacon process $\cdot$ Hydrogen chloride $\cdot$ Chlorine $\cdot$ Gold catalyst

Ekkehard Schwab now retired from BASF SE.

Electronic supplementary material The online version of this article (https://doi.org/10.1007/s10562-020-03204-0) contains supplementary material, which is available to authorized users.

Graham J. Hutchings

hutch@ cardiff.ac.uk

1 Cardiff Catalysis Institute, School of Chemistry, Main Building, Cardiff University, Park Place, Cardiff CF10 3AT, UK

2 BASF SE, Process Research \& Chemical Engineering, Carl-Bosch-Str. 38, 67056 Ludwigshafen am Rhein, Germany

\section{Introduction}

Chlorine is an important commodity chemical that is used in many applications. During use hydrogen chloride is often made as a by-product. Although hydrogen chloride has applications in the chemical industry, such as the hydrochlorination of acetylene, in many cases it is important that the chlorine is recovered. The Deacon reaction [1] is the industrial process whereby hydrogen chloride is oxidized to chlorine and water thereby permitting chlorine recovery for reuse. Due to equilibrium conditions, low operation temperatures are favorable in terms of possible conversion per pass.

$4 \mathrm{HCl}+\mathrm{O}_{2} \rightleftharpoons 2 \mathrm{Cl}_{2}+2 \mathrm{H}_{2} \mathrm{O}$ 
The Deacon reaction, named after its inventor Henry Deacon, was commercialised in 1874 . The first catalysts used were copper chlorides which were not stable above $400{ }^{\circ} \mathrm{C}$ and would start to evaporate when the operating temperature was $430-475{ }^{\circ} \mathrm{C}$. Since then there has been a substantial effort to increase the conversion efficiency of the reaction. The Shell-Chlor process [2] introduced in the 1960s used $\mathrm{CuCl}_{2}-\mathrm{KCl} / \mathrm{SiO}_{2}$ catalysts with a single fluidized-bed reactor, but the project was discontinued due to severe corrosion problems. Totsis et al. [3, 4] used copper-based catalysts in a dual fluidized-bed reactor which they developed to achieve a high $\mathrm{HCl}$ conversion to $\mathrm{Cl}_{2}$ with limited corrosion. Nieken and Watzenberger [5] employed a two-step fixed-bed reactor configuration to overcome corrosion problems. Sumitomo Chemicals subsequently developed a $\mathrm{RuO}_{2}-\mathrm{TiO}_{2}$ catalyst in a fixed-bed reactor [1]. The $\mathrm{RuO}_{2} / \mathrm{TiO}_{2}$ catalyst was found to exhibit both high activity at low temperature and stability. The rutile phase of $\mathrm{TiO}_{2}$ is the most effective form since it leads to improved growth of the epitaxial layers and this enable the catalyst to be very stable and active [6]. BASF researchers subsequently developed a $\mathrm{K}$ promoted $\mathrm{RuO}_{2} /$ $\mathrm{Al}_{2} \mathrm{O}_{3}$ catalyst [7]. Further improvements for the $\mathrm{RuO}_{2}$ catalysts were reported by Mondelli et al. [8] using a $\mathrm{RuO}_{2} /$ $\mathrm{SnO}_{2}-\mathrm{Al}_{2} \mathrm{O}_{3}$ catalyst in 2011 and by Teschner et al. using a $\mathrm{RuO}_{2}-\mathrm{SnO}_{2}$ catalyst [9]. Amrute et al. [10] reported $\mathrm{CeO}_{2}$ based catalysts but these were less active when compared with $\mathrm{RuO}_{2}$. They also studied $\mathrm{Cr}_{2} \mathrm{O}_{3}$ which has higher activity and stability than $\mathrm{Cu}$ based catalyst but leads to formation of chromyl chloride [11]. Based on these studies they subsequently investigated a delafossite $\mathrm{CuCrO}_{2}$ catalyst, which they found to be stable [12] but significantly less active than $\mathrm{RuO}_{2}$.

The proposed mechanism of the Deacon reaction can be divided into two steps; firstly, $\mathrm{HCl}$ adsorption by a metal oxide to form a metal (oxy)chloride. Secondly, oxidation of this species by $\mathrm{O}_{2}$ to regenerate the metal oxide and free $\mathrm{Cl}_{2}$. The mechanism proposed by Lopez et al. is based on experimental and DFT calculations using $\mathrm{RuO}_{2} / \mathrm{TiO}_{2}$ as a catalyst [6] involving the main steps of hydrogen abstraction from $\mathrm{HCl}$, recombination and desorption of atomic chlorine, hydroxyl recombination, water desorption, and oxygen adsorption. As Au-based catalysts have a high hydrogenation rate for an oxygen molecule, we considered that these steps could be achieved in parallel over $\mathrm{Au}$. $\mathrm{RuO}_{2}$ is also among the model compounds for various oxidation processes such as $\mathrm{CO}, \mathrm{H}_{2}, \mathrm{CH}_{4}$ [6] as are Au-based catalysts presently.

In a recent review, Over and Schomäcker [13] proposed that the dissociation energy of molecular oxygen could be used as a promising descriptor for activity with catalysts for which the oxygen dissociation energy was in the range 0 to $-100 \mathrm{~kJ} / \mathrm{mol}$ gave the highest activity. This observation further prompted us to consider whether supported Au catalysts could be used for the Deacon reaction as the oxygen dissociation energy is -48 to $-57 \mathrm{~kJ} / \mathrm{mol}$ [14]. We were further prompted to investigate the use of $\mathrm{Au}$ for this reaction since $\mathrm{Au} / \mathrm{C}$ catalysts have been found to be very active for acetylene hydrochlorination [15] and $\mathrm{CO}$ oxidation [16] and hence can use both $\mathrm{HCl}$ and $\mathrm{O}_{2}$ as substrates. In this study we report an investigation into the possible activity for $\mathrm{Au}$ in the Deacon reaction.

\section{Experimental Methods}

\subsection{Materials}

$\mathrm{RuCl}_{3} \cdot 3 \mathrm{H}_{2} \mathrm{O}$ (Aldrich, 99.98\%), $\mathrm{HAuCl}_{4} \cdot 3 \mathrm{H}_{2} \mathrm{O}$ (Aldrich $\geq 99.9 \%$ ), $\mathrm{TiO}_{2}$-rutile (nano-powder, Aldrich, 99.5\%), $\mathrm{Ce}\left(\mathrm{NO}_{3}\right)_{3} \cdot 6 \mathrm{H}_{2} \mathrm{O}$ (Aldrich, $99.999 \%$ ), ethanol (as abs. ethanol, Fisher Scientific), $\mathrm{Na}_{2} \mathrm{CO}_{3}$ (Fisher Scientific, anhydrous) and $\mathrm{NaOH}$ (VWR, pelleted $\geq 97 \%$ ) were used as received. Deionised water provided in house. Gases used as received were 5\% $\mathrm{HCl} / \mathrm{bal}$. $\mathrm{Ar}$ (BOC) and argon (Air Products). Moisture was removed from compressed air (in house) by passing through a filter containing molecular sieves prior to entering the reactor and similarly the $2 \% \mathrm{H}_{2} /$ bal. air (BOC) was dried by means of molecular sieves and an Agilent Technologies Gas Chromatograph moisture filter.

\subsection{Catalyst Preparation}

$7 \mathrm{wt} \% \mathrm{RuO}_{2} / \mathrm{TiO}_{2}$ was prepared by deposition-precipitation of $\mathrm{Ru}(\mathrm{OH})_{2}$. The $\mathrm{TiO}_{2}$ rutile support $(5 \mathrm{~g})$ was dispersed in distilled water $(250 \mathrm{ml})$ under continuous stirring. Then, an appropriate amount of $\mathrm{RuCl}_{3} \cdot 3 \mathrm{H}_{2} \mathrm{O}$ dissolved in $50 \mathrm{ml}$ of distilled water was added to the slurry. Precipitation of $\mathrm{Ru}(\mathrm{OH})_{2}$ was attained by adding an aqueous $\mathrm{NaOH}$ solution (10 wt\%) drop-wise to the slurry until $\mathrm{pH} 12$ was attained. The suspension was kept at room temperature for $1 \mathrm{~h}$ and then heated to $65{ }^{\circ} \mathrm{C}$ for $1 \mathrm{~h}$ with stirring. The suspension was cooled, filtered and washed with distilled water until the $\mathrm{pH}$ of the washing water was neutral, the material was dried at $120{ }^{\circ} \mathrm{C}$, and calcined in static air at $500{ }^{\circ} \mathrm{C}\left(10^{\circ} \mathrm{C} /\right.$ $\min$ ) for $5 \mathrm{~h}$.

$5 \mathrm{wt} \% \mathrm{Au} / \mathrm{TiO}_{2}$ was prepared using the deposition-precipitation method [17]. To prepare the catalyst (ca. $1 \mathrm{~g}$ ) $\mathrm{HAuCl}_{4} \cdot 3 \mathrm{H}_{2} \mathrm{O}(4.08 \mathrm{ml}, 12.25 \mathrm{mg} / \mathrm{ml})$ and $\mathrm{TiO}_{2}(0.95 \mathrm{~g}$, rutile) were added to distilled water $(100 \mathrm{ml})$ with vigorous stirring. This mixture was heated to $60{ }^{\circ} \mathrm{C}$ and the $\mathrm{pH}$ was adjusted to $\mathrm{pH} 7$ by the slow addition of aqueous $\mathrm{NaOH}$ $(0.1 \mathrm{M})$. The solution was left stirring for $1 \mathrm{~h}$ at the final $\mathrm{pH}$ before cooling in ice for $20 \mathrm{~min}$. The catalyst was then recovered by filtration, washed with distilled water until the $\mathrm{pH}$ of the washing water was neutral and dried in air $\left(110^{\circ} \mathrm{C}, 16 \mathrm{~h}\right)$. 
$5 \mathrm{wt} \% \mathrm{Au} / \mathrm{CeO}_{2}$ was prepared using the deposition precipitation method in an analogous way. Ceria was synthesised from $\mathrm{Ce}\left(\mathrm{NO}_{3}\right)_{3} \cdot 6 \mathrm{H}_{2} \mathrm{O}(2.5 \mathrm{~g})$ which was dissolved in ethanol and stirred for $1 \mathrm{~h}$, then left to evaporate. The recovered solid was then calcined for $6 \mathrm{~h}$ at $550{ }^{\circ} \mathrm{C}\left(1{ }^{\circ} \mathrm{C} /\right.$ min). Deionised water $(400 \mathrm{ml})$ was heated to $60^{\circ} \mathrm{C}$ and an appropriate amount of $\mathrm{HAuCl}_{4} \cdot 3 \mathrm{H}_{2} \mathrm{O}$ was then added and stirred for $15 \mathrm{~min}$. The ceria $(2 \mathrm{~g})$ was then added and $0.5 \mathrm{M}$ $\mathrm{Na}_{2} \mathrm{CO}_{3}$ was added until pH 8 was reached and the slurry was then left for $1 \mathrm{~h}$ before filtering. The solid was washed with 11 of hot deionised water and then dried at $110{ }^{\circ} \mathrm{C}$ for $5 \mathrm{~h}$. The dried material was calcined at 500 for $5 \mathrm{~h}\left(10^{\circ} \mathrm{C} /\right.$ min). The resulting catalysts comprised metallic Au with 2-5 nm nano-particles as described previously [17].

All catalysts were pelleted and sieved to between 400 and $600 \mu \mathrm{m}$ prior to loading in the reactor.

\subsection{Catalyst Characterisation}

Powder X-ray diffraction (XRD) analysis of the catalysts was carried out on a PANalytical X'pert Pro powder diffractometer (Malvern Panalytical, Malvern, UK) using a Cu source operated at $40 \mathrm{keV}$ and $40 \mathrm{~mA}$ with a $\mathrm{Ge}$ (111) monochromator to select $\mathrm{K} \alpha 1 \mathrm{X}$-rays. Patterns were analysed from measurements taken over the $2 \theta$ angular range $10^{\circ}-80^{\circ}$ (step size of $0.016^{\circ}$ ).

Scanning electron microscopy (SEM) was performed on a Tescan Maia3 (Tescan Orsay Holding, a.s., Czech Republic) field emission gun fitted (FEG-SEM) with an Oxford Instruments XMAXN 80. Images were acquired using the secondary electron (SE) and backscattered electron detectors (BSE). Samples were dispersed as a powder onto adhesive carbon Leit discs mounted onto aluminium stubs. Particle size distributions were recorded manually with a minimum of one hundred particles being examined.

\subsection{Deacon Reaction}

A reactor for the Deacon reaction was constructed wholly of Hastelloy C-276® (Supplementary Fig. S1). The gases (5\% $\mathrm{HCl} /$ bal. Ar and dry air or dry $2 \% \mathrm{H}_{2} /$ bal. air) were individually fed via calibrated mass flow controllers and mixed prior to flowing to the heated reactor (tube O.D. 0.375", I.D. $\left.0.236^{\prime \prime}\right)$. All lines prior to and after the reactor oven were heated to $100{ }^{\circ} \mathrm{C}$ to prevent condensation. The reactor tube was filled with alumina spheres (diameter $0.6 \mathrm{~mm}$ ) before and after the catalyst bed (Fig. S1c). Typically, catalyst $(250 \mathrm{mg})$ was placed between quartz wool at the centre point of the reactor tube, which itself was placed in a PID controlled reactor oven $\left( \pm 1{ }^{\circ} \mathrm{C}\right)$. The reactor effluent passed through an aqueous trap to dissolve the unreacted $\mathrm{HCl}$ and enable the $\mathrm{HCl}$ conversion to be calculated using an acid base titration. At ambient pressure, $4.39 \% \mathrm{HCl}$ and
$2.59 \% \mathrm{O}_{2}$ were passed through the reactor bypass (total flow $25 \mathrm{ml} / \mathrm{min})$. The reactor containing catalyst $(0.25 \mathrm{~g})$ was then heated to $500{ }^{\circ} \mathrm{C}$. When this reaction temperature was reached the bypass was switched so that the gases flowed over the reactor. Samples for titration were taken every $20 \mathrm{~min}$ and the reaction was continued for $4 \mathrm{~h}$. Reactions in the absence of catalyst showed no conversion and a standard $7 \mathrm{wt} \% \mathrm{Ru} / \mathrm{TiO}_{2}$ catalyst under these reaction conditions gave a steady state $\mathrm{HCl}$ conversion of $40 \%$ which under these reaction conditions is well below the equilibrium level of ca. $83 \%$ [18]. For reactions where $\mathrm{H}_{2}$ was included $0.25 \%$ $\mathrm{H}_{2}$ was added to the reaction gases. Argon was used to purge the reactor.

Reactant gases were passed into a liquid trap containing pre-weighed $\mathrm{H}_{2} \mathrm{O}$. These were exchanged periodically, and the loaded solutions titrated with a solution containing $0.1 \mathrm{M}$ $\mathrm{NaOH}$ and with a phenolphthalein indicator to determine the $\mathrm{HCl}$ concentration. From this the conversion of $\mathrm{HCl}$ was calculated.

\section{Results and Discussion}

An initial reaction was carried out using the rutile- $-\mathrm{TiO}_{2}$ support and this showed very limited activity of ca. $1 \%$ conversion (Fig. 1). The data are shown for reactions after $60 \mathrm{~min}$ on-line at $500{ }^{\circ} \mathrm{C}$ as in the initial period $\mathrm{HCl}$ was adsorbed onto the catalyst/support; consequently, the data are shown when a steady-state activity was observed. The $5 \mathrm{wt} \% \mathrm{Au} /$ $\mathrm{TiO}_{2}$ catalyst showed a modest improvement in activity of

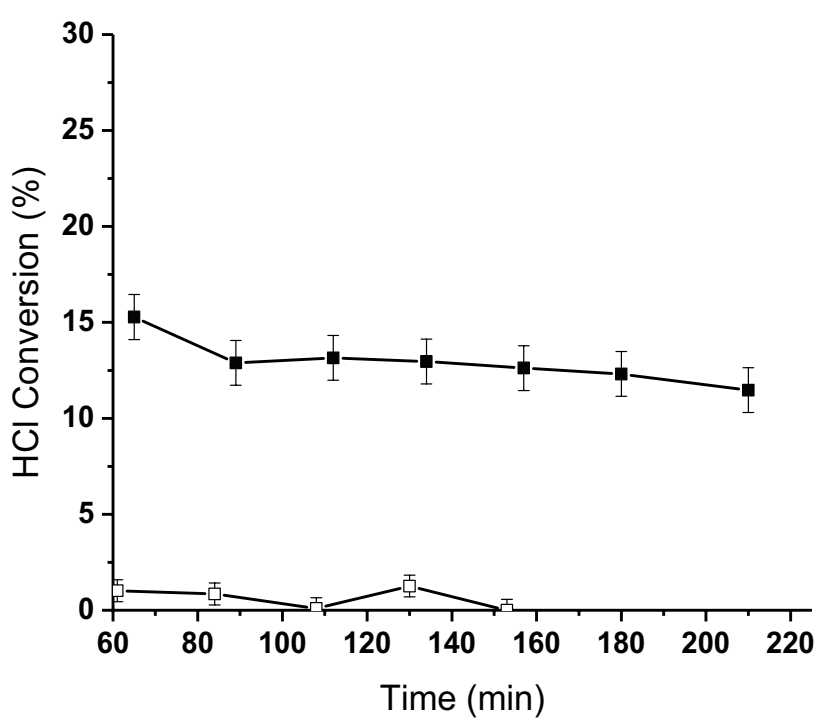

Fig. 1 Comparison of the $\mathrm{HCl}$ conversion over $\mathrm{TiO}_{2}$ (open square) and $5 \% \quad \mathrm{Au} / \mathrm{TiO}_{2}$ (filled square) catalyst. Reaction conditions: Total flow $=25 \mathrm{ml} / \mathrm{min} ;[\mathrm{HCl}]=4.39 \% ;\left[\mathrm{O}_{2}\right]=2.59 \% ; \mathrm{T}=500{ }^{\circ} \mathrm{C}$; cat. $=250 \mathrm{mg}$ 
ca. $12 \% \mathrm{HCl}$ conversion (Fig. 1). It should be noted that the equilibrium $\mathrm{HCl}$ conversion under these dilute reaction conditions at $500{ }^{\circ} \mathrm{C}$ is $72.7 \%$ (Supplementary Fig. S2). The catalyst was characterised by XRD and SEM prior to reaction in both the as-made and as-pelleted state (Supplementary Fig. S3). The diffraction patterns for both the fresh and pelleted catalysts were consistent with the rutile- $\mathrm{TiO}_{2}$ diffraction pattern (JCPDS: 88-1175) with strong reflections at $2 \theta=27.6^{\circ}, 36.3^{\circ}$ and $54.5^{\circ}$. No Au reflections (typically $2 \theta=38^{\circ}, 44^{\circ}$ and $65^{\circ}$ ) are visible in the diffraction patterns and we consider that the adsorbed nano-particles are $\leq 5 \mathrm{~nm}$ in diameter. Electron microscopy (Supplementary Fig. S3) of the fresh and pelleted catalysts were obtained with the backscatter and in-line detectors and Au nano-particles are visible, however, in general these are $<7 \mathrm{~nm}$ in diameter. From the images the dispersion of Au does not appear efficient, with some aggregates of Au nano-particles present. However, this is close to the limit of the detector and previous work using a comparative preparation has shown particles ranging from 2 to $5 \mathrm{~nm}$ which has been shown to be optimal for many redox reactions [17].

It is clear that $\mathrm{Au} / \mathrm{TiO}_{2}$ is not an effective Deacon catalyst, as the activity for a reference $7 \mathrm{wt} \% \mathrm{RuO}_{2} / \mathrm{TiO}_{2}$ catalyst gave ca. $40 \% \mathrm{HCl}$ conversion at $500{ }^{\circ} \mathrm{C}$ for $3 \mathrm{~h}$ time-on-line under these conditions (Supplementary Fig. S4). We also investigated the $5 \mathrm{wt} \% \mathrm{Au} / \mathrm{CeO}_{2}$ catalyst and $\mathrm{CeO}_{2}$ at $500{ }^{\circ} \mathrm{C}$ under these conditions (Fig. 2) and in this case Au gave no increase in activity over that observed for the $\mathrm{CeO}_{2}$ support. Over both materials the $\mathrm{HCl}$ conversion can be observed to decrease from ca. 25 to $15 \%$ from 120 min time-on-line. At this stage, we therefore concluded that $\mathrm{Au}$ is not an effective

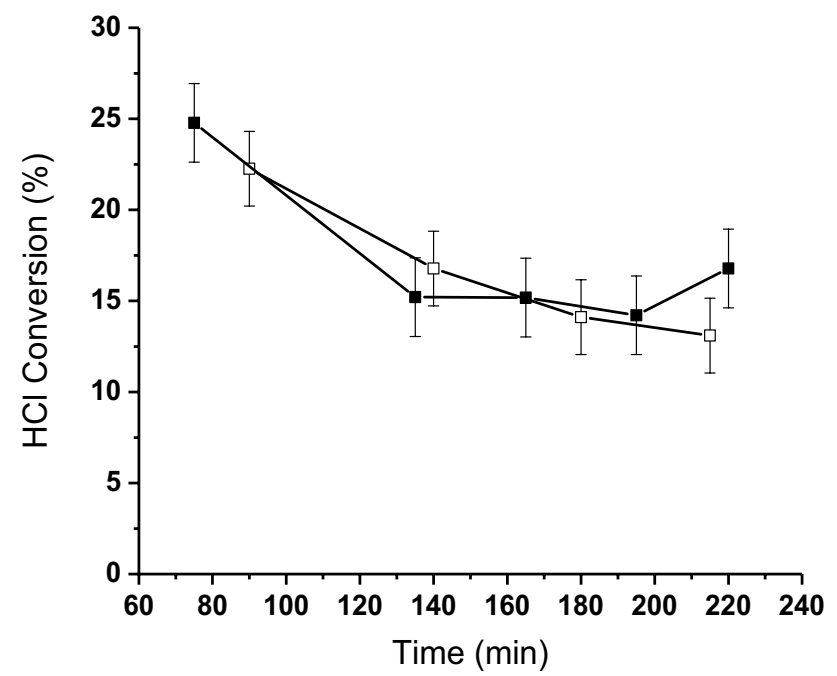

Fig. 2 Comparison of the $\mathrm{HCl}$ conversion over $\mathrm{CeO}_{2}$ (open square) and $5 \% \mathrm{Au} / \mathrm{CeO}_{2}$ (filled square) catalyst. Reaction conditions: Total flow $=25 \mathrm{ml} / \mathrm{min} ;[\mathrm{HCl}]=4.39 \% ;\left[\mathrm{O}_{2}\right]=2.59 \% ; \mathrm{T}=500{ }^{\circ} \mathrm{C}$; cat. $=250 \mathrm{mg}$ catalyst for the Deacon reaction, which suggests that using oxygen dissociation energy is not an appropriate indicator of activity for this reaction. It is possible that $\mathrm{Au}$ cannot simultaneously activate $\mathrm{HCl}$ and $\mathrm{O}_{2}$. In the acetylene hydrochlorination reaction it is proposed that [15] the $\mathrm{Au}^{+}$initially activates $\mathrm{HCl}$ and the $\mathrm{Au}^{+} / \mathrm{HCl}$ complex interacts with the acetylene and perhaps this pathway is not effective with $\mathrm{O}_{2}$.

It is known that dioxygen cannot by itself initiate a radical reaction but can in effect propagate such reactions once an initial activation has been achieved. One such initiator can be molecular hydrogen, which will then lead to the formation of a reactive hydroperoxy species. Indeed, previous studies using gold catalysts for propene oxidation [19] have shown that selective oxidation to propene oxide requires the addition of $\mathrm{H}_{2}$ as a co-reactant. With this in mind, we carried out the Deacon reaction under the same reaction conditions at $500{ }^{\circ} \mathrm{C}$ but with the addition of $\mathrm{H}_{2}(0.25 \%)$. The results shown in Fig. 3 show that the catalyst activity can be improved for both $\mathrm{TiO}_{2}$ and the $5 \mathrm{wt} \% \mathrm{Au} / \mathrm{TiO}_{2}$ catalyst, with the effect being more marked when $\mathrm{Au}$ is present (Figs. 1 and 3). However, the steady state activity was still considerably lower that observed for the $7 \mathrm{wt} \% \mathrm{RuO}_{2} / \mathrm{TiO}_{2}$ catalyst in the absence of $\mathrm{H}_{2}$ (Supplementary Fig. S3). The observation that $\mathrm{H}_{2}$ can enhance the Deacon reaction with $\mathrm{TiO}_{2}$ alone is a very interesting observation. For the $\mathrm{Au} / \mathrm{TiO}_{2}$ catalysed propene epoxidation with $\mathrm{H}_{2}$ and $\mathrm{O}_{2}$ it is often discussed that activation occurs at the contact rim between the Au nano-particles and the support [20]. However, in this case activation of the $\mathrm{H}_{2}$ is occurring without the need for the gold interfacial sites and this is an effect that warrants further investigation.

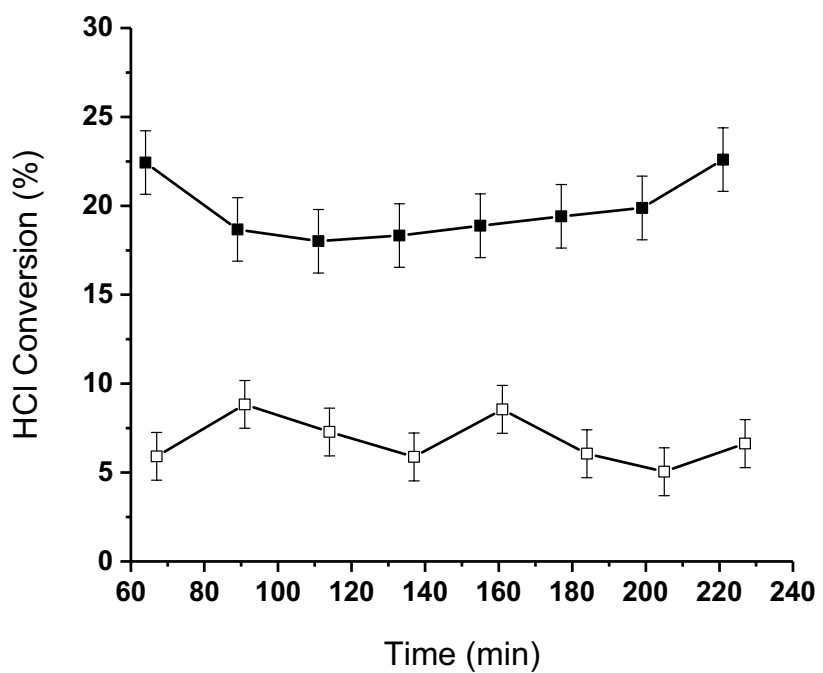

Fig. 3 Comparison of the $\mathrm{HCl}$ conversion over $\mathrm{TiO}_{2}$ (open square) and $5 \% \mathrm{Au} / \mathrm{TiO}_{2}$ (filled square) catalyst with $\mathrm{H}_{2}$. Reaction conditions: Total flow $=25 \mathrm{ml} / \mathrm{min} ;[\mathrm{HCl}]=4 \% ;\left[\mathrm{O}_{2}\right]=2 \% ;\left[\mathrm{H}_{2}\right]=0.25 \%$; $\mathrm{T}=400{ }^{\circ} \mathrm{C}$; cat. $=250 \mathrm{mg}$ 


\section{Conclusions}

While gold can be an effective catalyst for a range of oxidation reactions and is acknowledged to be the best catalyst for acetylene hydrochlorination [15] our brief study shows that gold does not show promise for the Deacon reaction; gold is not able to simultaneously activate $\mathrm{O}_{2}$ and $\mathrm{HCl}$ which is a requirement for the Deacon reaction. When $\mathrm{H}_{2}$ is introduced as a co-reactant the situation changes and gold does display some Deacon activity.

Acknowledgements We thank BASF for financial support. We thank Steve Morris for technical support and Nia Richards for assistance with the reactor schematic.

\section{Compliance with Ethical Standards}

Conflict of interest The authors declare no conflict of interest.

Open Access This article is licensed under a Creative Commons Attribution 4.0 International License, which permits use, sharing, adaptation, distribution and reproduction in any medium or format, as long as you give appropriate credit to the original author(s) and the source, provide a link to the Creative Commons licence, and indicate if changes were made. The images or other third party material in this article are included in the article's Creative Commons licence, unless indicated otherwise in a credit line to the material. If material is not included in the article's Creative Commons licence and your intended use is not permitted by statutory regulation or exceeds the permitted use, you will need to obtain permission directly from the copyright holder. To view a copy of this licence, visit http://creativecommons.org/licenses/by/4.0/.

\section{References}

1. Pérez-Ramírez J, Mondelli C, Schmidt T et al (2011) Sustainable chlorine recycling via catalysed $\mathrm{HCl}$ oxidation: from fundamentals to implementation. Energy Environ Sci 4:4786-4799

2. Johnson AJ, Cherniavsky AJ (1951) Chlorine production. US Patent 2,542,961

3. Pan HY, Minet RG, Benson SW, Tsotsis TT (1994) Process for converting hydrogen chloride to chlorine. Ind Eng Chem Res 33:2996-3003

4. Mortensen M, Minet RG, Tsotsis TT, Benson SW (1999) The development of a dual fluidized-bed reactor system for the conversion of hydrogen chloride to chlorine. Chem Eng Sci $54: 2131-2139$
5. Nieken U, Watzenberger O (1999) Periodic operation of the Deacon process. Chem Eng Sci 54:2619-2626

6. López N, Gómez-Segura J, Marín RP, Pérez-Ramírez J (2008) Mechanism of $\mathrm{HCl}$ oxidation (Deacon process) over $\mathrm{RuO}_{2}$. J Catal 255:29-39

7. Henze G, Urtel H, Sesing M, et al (2011) Catalyst comprising ruthenium and nickel for the oxidation of hydrogen chloride. US Patent 0268649

8. Mondelli C, Amrute AP, Krumeich $\mathrm{F}$ et al (2011) Shaped $\mathrm{RuO}_{2} /$ $\mathrm{SnO}_{2}-\mathrm{Al}_{2} \mathrm{O}_{3}$ catalyst for large-scale stable $\mathrm{Cl}_{2}$ production by $\mathrm{HCl}$ oxidation. ChemCatChem 3:657-660

9. Teschner D, Farra R, Yao L et al (2012) An integrated approach to Deacon chemistry on $\mathrm{RuO}_{2}$-based catalysts. J Catal 285:273-284

10. Amrute AP, Mondelli C, Moser M et al (2012) Performance, structure, and mechanism of $\mathrm{CeO}_{2}$ in $\mathrm{HCl}$ oxidation to $\mathrm{Cl}_{2}$. $\mathrm{J}$ Catal 286:287-297

11. Amrute AP, Mondelli C, Pérez-Ramírez J (2012) Kinetic aspects and deactivation behaviour of chromia-based catalysts in hydrogen chloride oxidation. Catal Sci Tech 2:2057-2065

12. Amrute AP, Larrazábal GO, Mondelli C, Pérez-Ramírez J (2013) $\mathrm{CuCrO}_{2}$ delafossite: a stable copper catalyst for chlorine production. Angew. Chem. Int. Ed. 52:9772-9775

13. Over H, Schomäcker R (2013) What makes a good catalyst for the Deacon process? ACS Catal 3:1034-1046

14. Roldan A, Ricart JM, Illas F, Pacchioni G (2010) $\mathrm{O}_{2}$ adsorption and dissociation on neutral, positively and negatively charged $\mathrm{Au}_{n}$ ( $n=5-79)$ clusters. Phys Chem Chem Phys 12:10723-10729

15. Malta G, Kondrat SA, Freakley SJ et al (2017) Identification of single-site gold catalysts in acetylene hydrochlorination. Science 355:1399-1402

16. Haruta M, Yamada N, Kobayashi T, Iijima S (1989) Gold catalysts prepared by coprecipitation for low-temperature oxidation of hydrogen and of carbon monoxide. J Catal 115:301-309

17. Dimitratos N, Villa A, Bianchi CL et al (2006) Gold on titania: Effect of preparation method in the liquid phase oxidation. Appl Catal A: General 311:185-192

18. Zhao J, Fu D, Song N, Yuan X, Bi X (2019) Reaction kinetics of $\mathrm{HCl}$ catalytic oxidation over a supported cu-based composite industrial catalyst. Ind Eng Chem Res 58:9246-9256

19. Haruta M, Uphade BS, Tsubota S, Miyamoto A (1998) Selective oxidation of propylene over gold deposited on titanium-based oxides. Res Chem lntermed 24:329-336

20. Nijhuis TA, Visser T, Weckhuysen BM (2005) Mechanistic study into the direct epoxidation of propene over gold/titania catalysts. J Phys Chem B 109:19309-19319

Publisher's Note Springer Nature remains neutral with regard to jurisdictional claims in published maps and institutional affiliations. 